Guambe, R. Mutemba, B. \& Matavele, H. (2020). Etnomatemática e a construção de uma educação multicultural na escola. Revista Latinoamericana de Etnomatemática, 13(3), 62-87.DOI:

10.22267/relatem.20133.65

Artículo recibido el 04 de junio de 2020. Aceptado para publicación el 25 de noviembre de 2020

\title{
Desempenho dos alunos na lógica formal e relação com a sua língua e classe social
}

\section{Performance of students in formal logic and relationship with their language and social class}

\author{
Ribas Guambe ${ }^{1}$ \\ Balbina Mutemba ${ }^{2}$ \\ Hilária Matavele ${ }^{3}$
}

\begin{abstract}
Resumo
Moçambique é uma sociedade multilíngue e, consequentemente multicultural, com mais de 40 línguas nativas. Todas elas são línguas Bantu, com exceção do Português, a língua oficial desde a independência de Moçambique, e poucas de poucos imigrantes residentes no país. Segundo o Censo Geral de 2017, somente cerca de $47 \%$ da população tinha o Português como língua materna (INE, 2019). As línguas dominantes no local onde a pesquisa foi desenvolvida são: Ci-Changana, Ci-Ronga e Ci-Tshwa, todas de origem Tsonga e mutuamente entendíveis entre os falantes.

Apesar de apenas cerca de $26 \%$ das crianças em idade escolar se comunicarem em Português, esta é a língua de ensino em Moçambique. Esta informação é relevante porque, no contexto moçambino, falar a língua oficial, confere ao falante um status diferenciado em relação aos demais, isto é, quem fala esta língua, teoricamente, tem status social mais elevado.

Os objectivos da pesquisa são (i) explorar as estratégias preferidas pelos alunos, de diferentes extractos sociais e linguísticos, quando resolvem problemas sobre lógica e (ii) relacionar o desempenho na resolução de uma questão de lógica apresentada na pesquisa e o sucesso escolar.

A pesquisa é de carácter qualitativo, apoiada na abordagem discursiva de aprendizagem de matemática.

Participaram nela 8 alunos, da $10^{\text {a }}$ Classe de uma escola localizada no meio semi-rural. Os participantes com melhor aproveitamento escolar mostraram possuir as regras de reconhecimento do contexto em alusão, isto é, resolveram o problema envolvendo o raciocínio lógico com base nas proposições apresentadas no enunciado, e a partir dos significados construíram textos legitimamente aceites para aquele contexto, enquanto os com baixo aproveitamento baseavam-se nas suas vivências do quotidiano para produzir os seus textos, o que revela falta de reconhecimento do contexto do problema.
\end{abstract}

Palavras-chaves: Lógica, Língua, Estatuto social, Regras de reconhecimento e de realização.

${ }^{1} \mathrm{Ph}$. D. Senior Lecturer and Researcher in Mathematics Education. Affiliation: Department of Mathematics, Faculty of Sciences Eduardo Mondlane University, Maputo, Mozambique P. O. Box 257. E-mail: ribas.guambe@uem.ac.mz; ribasg71@gmail.com

${ }^{2} \mathrm{Ph} . \mathrm{D}$. Senior Lecturer and Researcher in Mathematics Education. Affiliation: Department of Mathematics, Faculty of Sciences Eduardo Mondlane University, Maputo, Mozambique P. O. Box 257. E-mail: balbina.muthemba@uem.ac.mz; balbina.muthemba@gmail.com

${ }^{3} \mathrm{Ph} . \mathrm{D}$. Senior Lecturer and Researcher in Mathematics Education and Theory and Curriculum Development Affiliation: Department of Mathematics, Faculty of Sciences Eduardo Mondlane University, Maputo, Mozambique P. O. Box 257. E-mail: hilaria.matavele@uem.ac.mz; himatavele@yahoo.com.br 
Guambe, R. Mutemba, B. \& Matavele, H. (2020). Etnomatemática e a construção de uma educação multicultural na escola. Revista Latinoamericana de Etnomatemática, 13(3), 00-00.DOI:

\begin{abstract}
Mozambique is a multilingual and therefore multicultural society, with more than 40 native languages. All of them are Bantu languages, with the exception of Portuguese, the official language since the independence of Mozambique, and few of the few immigrants' residents in the country.

According to the 2017 General Census, only about $47 \%$ of the population had Portuguese as their mother tongue (INE, 2019). The dominant languages at the place where the research was carried out are: Ci-Changana, CiRonga and Ci-Tshwa, all of Tsonga origin and mutually understandable among speakers.

Although only about $26 \%$ of school-age children communicate in Portuguese, this is the language of instruction in Mozambique. This information is relevant because, in the Mozambican context, speaking the official language, gives the speaker a differentiated status in relation to the others, that is, whoever speaks this language, theoretically, has a higher social status.

The objectives of the research are (i) to explore the strategies preferred by the students, from different social and linguistic extracts, when solving problems about logic and (ii) to relate performance in solving a question of logic presented in the research and school success.

The research is qualitative, supported by the discursive approach to learning mathematics. Eight students from the 10th Class of a school located in the semi-rural environment participated in it. The participants with better school performance showed to have the rules of recognition of the context in allusion, that is, they solved the problem involving logical reasoning based on the propositions presented in the statement, and from the meanings constructed texts legitimately accepted for that context, while with low performance they were based on their daily experiences to produce their texts, which reveals a lack of recognition of the context of the problem.
\end{abstract}

Keywords: Logic, Language, Social status, Rules of recognition and achievement.

\title{
1. INTRODUÇÃO
}

A pesquisa visa, por um lado, explorar como é que os alunos reconhecem o contexto num problema de lógica com contexto do quotidiano, seleccionam os significados e os tornam públicos e, por outro, relacionar o desempenho na resolução do problema com o sucesso escolar na disciplina de Matemática, considerando também a condição social e linguística dos alunos. Concretamente, o estudo pretende verificar a influência da classe social no desempenho apropriado dos alunos de uma escola moçambicana, analisando os seus discursos na resolução de um problema de lógica com contexto realista, de modo a perceber se existe diferença entre a forma de proceder dos participantes desta pesquisa quando elaboram os seus argumentos, de acordo com a sua classe social, e comparar o desempenho com o sucesso escolar. Assim, é relevante considerar como é vista, por alguns autores, a relação entre a aquisição de conhecimentos e a classe social. 
Zevenbergen $(1995 ; 1998 ; 2000)$ aborda o papel do contexto social na comunicação em sala de aula e no processo de aquisição do conhecimento escolar. Zevenbergen \& Lerman (2004) analisaram o contexto sócio-político da sala de aula de Matemática com base na estrutura teórica de Bernstein, mais concretamente as regras de realização e de reconhecimento.

Tendo estes autores como base, é analisada a comunicação entre os alunos ao resolverem o problema de lógica, buscando perceber como as regras de reconhecimento e de realização são evidênciadas.

De acordo com Bernstein (1996), a produção textual em resposta à uma dada tarefa, depende de o aluno possuir uma orientação de codificação específica para o contexto do problema. $\mathrm{O}$ aluno distingue cada contexto com base nas suas características específicas, sendo para isso necessário que adquira as regras de reconhecimento para esse contexto, no caso vertente, a análise das proposições dadas a partir das quais extrai uma conclusão. As regras de reconhecimento permitem que o aluno selecione os significados que podem ser legitimados pelo professor, e produza um texto para aquele contexto, isto é, que adquira as regras de realização. A produção de um texto legítimo, o que se espera que seja a resposta à questão, requer que o aluno saiba selecionar os significados apropriados, interpretando as condições do problema e saiba usá-los no contexto do problema, relacionando as proposições para extrair uma conclusão com base na exclusão das alternativas não consistentes com as premissas.

Baseando-se na teoria de Bernstein, Cooper \& Dunne (2000) constataram que na resolução de problemas matemáticos com contextos realistas os alunos da classe trabalhadora relacionavam as tarefas com suas experiências específicas fora da escola, a fim de encontrar a resposta, em vez de se concentrarem na estrutura matemática do problema. Em contraste, os alunos da classe média pareciam mais propensos a reconhecer o problema de resolução de contexto como exigindo uma resposta em termos de um 'texto legítimo' dentro do contexto da matemática escolar. Em termos da teoria de Bernstein (1996), eles estão em posse de reconhecimento e de realização de regras para este contexto, e, portanto, não deixam que a sua experiência do mundo real interfira com o seu raciocínio matemático na produção duma resposta "adequada". Estas conclusões são unanimes com as encontradas por Taylor \& 
Guambe, R. Mutemba, B. \& Matavele, H. (2020). Etnomatemática e a construção de uma educação multicultural na escola. Revista Latinoamericana de Etnomatemática, 13(3), 00-00.DOI:

$10.22267 /$ relatem.20133.65

Vinjevold (1999), que afirmam que as crianças da classe trabalhadora têm mais dificuldade em adquirir os códigos de linguagem elaborados e princípios especializados de classificação do que as crianças de classe média, que reforçam na escola os princípios que estão na base do conhecimento escolar, trazidos do meio familiar, onde se destacam fundamentalmente o nível sociocultural e académico dos adultos que com eles lidam. A abordagem destes autores traz uma contribuição para esta pesquisa, no que se refere a dificuldade das crianças da classe trabalhadora na aquisição dos códigos de linguagem elaborados e princípios especializados de classificação, que estabelecem regras de reconhecimento específicas para que elas reconheçam a especificidade de um determinado contexto. Consequentemente, os textos por elas produzidos não são legitimados no contexto devido a ausência das regras de realização.

Para delimitar a área do presente estudo foram colocadas as seguintes questões de pesquisa: (1) Quais são as estratégias preferidas pelos alunos, de diferentes estratos sociais e linguísticos, quando resolvem problemas sobre lógica? (2) Qual a relação entre o desempenho na resposta ao problema e o sucesso escolar?

\section{ORIENTAÇÃO TEÓRICA}

A aprendizagem da matemática escolar pressupõe a iniciação dos alunos numa prática discursiva específica, que envolve os sinais e as regras procedimentais da matemática escolar (Gellert, 2009).

A especialização dos discursos escolares revela que há uma fronteira entre o que pode ser ensinado ou não na sala de aula, entre o conhecimento escolar formal e o conhecimento informal, o escolar e o quotidiano, tanto do professor quanto do aluno.

A produção de um texto, legitimamente aceite na sala de aula, requer não apenas que o aluno reconheça o contexto do problema, mas também, que adquira as regras de realização neste contexto (Bernstein, 1996). Quando o aluno adquire as regras de reconhecimento, está capaz de diferenciar o tipo de discurso permitido na resolução do problema verbal que vivencia uma situação do quotidiano, mas pelo contexto em que é apresentado, requer uma interpretação da sala de aula. Tendo as regras de reconhecimento o aluno escolhe significados 
diferenciados para o contexto em que se encontra para se comunicar, na aula de Matemática, no pátio da escola, no laboratório de informática, etc. A rigidez exigida aos discursos numa aula de Matemática é mais flexível quando os discursos são tornados públicos no laboratório de Informática, sendo muito ténue a fronteira entre o conhecimento escolar e o do quotidiano no pátio de uma escola.

Na presente situação, o aluno tem que reconhecer que está numa aula de Matemática, e por isso a argumentação deve se basear nas condições do problema para concluir sobre o destino de cada viajante, apresentando evidências que sustentam essa conclusão, como é esperado numa questão de lógica formal, e desta forma elaborar um discurso adequado.

Se por um lado o estatuto social interfere na forma como o aluno reconhece as características do contexto, por outro, a linguagem materna é também um obstáculo para a compreensão da estrutura das frases da língua de ensino. De acordo com Capelin \& Martins (2016) a linguagem materna, com suas influências culturais, suas gírias contribuem em grande medida para as dificuldades que os alunos encontram na compreensão da linguagem formal, interferindo a linguagem não formal, usada pelos alunos, muitas vezes no entendimento do sentido real dos textos.

Rauber et al. (2003) citado por Munhoz et al (2013) chama a atenção para as dificuldades que alunos universitários enfrentam na interpretação do que lêem por não terem aprendido a captar os significados escondidos nos textos. A assunção destes pesquisadores sobre dificuldades dos alunos universitários em captar o que está por detrás das palavras do texto, permite imaginar quão complexa é a situação nos níveis de ensino inferiores, como é o caso do público-alvo desta pesquisa, constituído por alunos do ensino secundário básico de uma zona semi-rural onde as crianças falam predominantemente a suas línguas maternas em detrimento da língua oficial.

O ponto de vista dos pesquisadores mencionados é útil e importante para este estudo na medida em que este busca, sobretudo, entender como é que a condição social e a língua materna que os alunos usam, habitualmente, interferem nas estratégias usadas pelos alunos 
Guambe, R. Mutemba, B. \& Matavele, H. (2020). Etnomatemática e a construção de uma educação multicultural na escola. Revista Latinoamericana de Etnomatemática, 13(3), 00-00.DOI:

$10.22267 /$ relatem.20133.65

na resolução do problema de lógica formal, relacionando o seu desempenho com o sucesso escolar.

\section{DESENHO E MÉTODO DE PESQUISA}

O desenho e o método são cruciais para o alcance do propósito da pesquisa. Esta pesquisa, por natureza de carácter qualitativo, apoiada na abordagem discursiva de aprendizagem de matemática, destina-se a analisar o discurso dos alunos ao resolverem um problema de lógica com vista a perceber que estratégias são usadas pelos alunos e como é que o desempenho se relaciona com o sucesso escolar.

Participaram na pesquisa 8 alunos da décima classe, de uma escola do distrito de Moamba, um distrito localizado no sul de Moçambique, com idades compreendidas entre 16 e 21 anos, todos falantes de Português, língua oficial, e proficientes nas suas línguas locais.

A principal actividade do distrito onde o estudo decorreu é agrária, compreendendo a produção agrícola e pecuária e também algum pequeno comércio que beneficia da proximidade da fronteira com a República da África do Sul. Além disso, há algum sector de Serviço Público que emprega algumas pessoas.

Importa referir que a idade de frequência nesta classe deveria ser aos 15 anos, considerando que a idade normal de entrada na escola em Moçambique é aos 6 anos. No distrito em causa, como em muitas regiões de Moçambique, os alunos entram tarde na escola por várias razões, agravando-se a situação dos atrasos pelo facto de desistência temporária dos alunos para se dedicarem a colheita nas machambas familiares ou ao comércio fronteiriço.

Foi administrado um questionário (Anexo I) com objectivo de caracterizar socialmente os participantes, através de informações pessoais: género, intervalo de idade, língua materna e de comunicação quotidiana fora do contexto escolar, de modo a estratificar os participantes em grupos sociais. Este questionário sobre o histórico dos participantes foi inspirado no modelo do inquérito dos censos gerais de população em Moçambique, cujas diferentes versões foram discutidas com técnicos do Instituto Nacional de Estatística, da Direç̧ão de Economia Agrária do Ministério da Agricultura. Instituições que, regularmente trabalham 
com as comunidades na recolha de dados sensíveis. A última versão do questionário foi discutida com três académicos em funções na Universidade Eduardo Mondlane, respectivamente um Sociólogo, um Antropólogo e um Linguista. A selecção destas 3 entidades tem a ver com a natureza do questionário que aborda questões muito pessoais e sensíveis. Pareceu-nos que a natureza dum Sociólogo salvaguardaria na escolha do tipo e forma de apresentar questões. O Antropólogo é alguém, por excelência, com habilidade de apresentar questões e interpretar as respostas de forma abrangente, em respeito à sua actividade. O Linguista foi abordado particularmente para refinar a forma de apresentação das questões sob o ponto de vista linguístico formal.

Adicionalmente, analisou-se o desempenho escolar dos participantes, com base nas pautas de aproveitamento do final do trimestre fornecidas pelo Sector Pedagógico da escola onde se realizou a pesquisa, uma vez que, de acordo com Jablonka (2007), as competências de leitura são importantes para responder às questões matemáticas, especialmente tendo em conta que, a tarefa em consideração é essencialmente contextualizada. Através deste instrumento pretendia-se saber se havia alguma relação entre o aproveitamento escolar e a estratégia dos participantes na resolução do problema.

A colecta de dados foi feita por meio da observação da resolução de uma tarefa de lógica. As conversas dos grupos durante a resolução da tarefa foram gravadas, com autorização dos participantes, e imediatamente transcritas. As transcrições podem ser lidas no apêndice no final deste texto.

A tarefa de lógica não era, necessariamente, de matemática, contudo, vista no contexto de sala de aula pode ser avaliado o ponto de vista dos alunos, se valorizam o quotidiano ou se conseguem trabalhar no contexto meramente lógico e escolar.

Os discursos dos participantes foram analisados tendo em atenção elementos da teoria de Bernstein e procurou-se a relação entre o desempenho na resolução da tarefa e o seu desempenho escolar. 
Guambe, R. Mutemba, B. \& Matavele, H. (2020). Etnomatemática e a construção de uma educação multicultural na escola. Revista Latinoamericana de Etnomatemática, 13(3), 00-00.DOI:

10.22267/relatem.20133.65

\section{ANÁLISE DOS RESULTADOS}

A sociedade moçambicana per si é de classes baixas e/ou com poucas posses de subsistência. Contudo, em qualquer comunidade o acesso aos recursos é sempre diferenciado. Foi tendo em conta este acesso diferenciado que a sistematização dos questionários permitiu formar três grupos de classes aqui denominadas por: alta, média e baixa

Para a resolução da questão formaram-se três grupos assim distribuidos:

- Grupo I: Dois meninos da classe alta e uma menina da classe média todos têm o Português como língua materna e se comunicam regularmente por esta mídia.

- Grupo II: Duas meninas da classe baixa, comunicam-se regularmente em línguas Bantu, localmente faladas, recorrendo à mídia de instrução (Português) só no meio escolar.

- Grupo III: Duas meninas da classe média cuja língua materna é uma das línguas Bantu, e um menino da classe alta cuja língua materna é português. As meninas comunicam-se regularmente nas línguas Bantu enquanto que o rapaz em Português.

Apesar de todos os participantes serem falantes de uma das línguas locais e, ser comum entre as pessoas em Moçambique introduzir termos das línguas maternas nas conversas, mesmo em estabelecimentos públicos, os participantes usaram apenas a língua Portuguesa durante os debates, salvo algumas pequenas exclamações feitas nas línguas Bantu, apesar do nível de diferença no seu domínio da língua ofícial.

A questão lógica apresentada aos alunos é:

Magaia, Manhique e Sumbane vivem neste distrito. Eles planificam viajar: Um vai à Maputo, outro vai à Praia de Bilene e outro vai à reserva de Kruger Park.

Sabes que:

1. Magaia pede emprestado carro à pessoa que vai à Maputo.

2. A pessoa que vai à Maputo e o Manhique vão com as suas crianças. 
3. Magaia vai ficar fora por mais tempo em relação a pessoa que vai à Praia de Bilene.

\section{A pergunta é: Quem vai a onde?}

Os alunos analisaram a tarefa em duas perspectivas. Uns consideraram como uma narrativa sobre pessoas que estão planeando viajar e conceituaram-na como uma tarefa relacionada com atividades domésticas e de lazer. A outra parte dos alunos considerou-a como uma tarefa puramente lógica que pode ser resolvida ignorando, completamente, todas as informações locais sobre o contexto.

O problema pode ser considerado como uma tarefa matemática da escola devido à sua proximidade com a lógica formal. Por essa razão, a tarefa deve ser contextualizada como uma questão de lógica. Para responder à pergunta, os alunos têm que contextualizar a tarefa como lógica e, com esta lente precisam de considerar apenas três viajantes, três destinos e a estrutura linguística das três frases/condições sobre as relações entre os três viajantes. Ler as três frases apenas em relação a este conteúdo relevante resultaria em:

- A primeira frase permite concluir que Magaia não vai à Maputo porque ele pede emprestado o carro da pessoa que vai à este destino. A terceira frase permite concluir que Magaia não viaja para a Praia do Bilene, pois, afirma-se que ele (Magaia) faz algo diferente, ficar mais tempo do que aquele que vai à Praia de Bilene. Magaia é excluído de dois destinos num conjunto de três, o que significa que ele viaja para o terceiro: Reserva de Kruger Park.

- A segunda proposição exclui Manhique do destino Maputo e sabe-se que o destino Reserva do Kruger Park foi tomado por Magaia, então o que resta para Manhique é a Praia do Bilene. Consequentemente, Sumbane vai ao destino restante que é Maputo.

Entre as diversas estratégias na resolução desta tarefa, o aluno pode utilizar uma tabela apresentando os três viajantes e os três destinos e, em seguida, interpretar e analisar as condições propostas, assinalando, por exemplo, N (o que significa não) e S (significando sim): A primeira e a terceira proposições permitem colocar o $\mathrm{N}$ na primeira e segunda 
Guambe, R. Mutemba, B. \& Matavele, H. (2020). Etnomatemática e a construção de uma educação multicultural na escola. Revista Latinoamericana de Etnomatemática, 13(3), 00-00.DOI:

10.22267/relatem.20133.65

colunas de destino para Magaia, a segunda frase permite assinalar $\mathrm{N}$ na primeira coluna de destino para Manhique.

\begin{tabular}{|l|c|c|c|}
\hline \multirow{2}{*}{ Viajante } & \multicolumn{3}{|c|}{ Destino } \\
\cline { 2 - 4 } & Maputo & Praia do Bilene & Reserva de Kruger Park \\
\hline Magaia & $N$ & $N$ & $S$ \\
\hline Manhique & $N$ & $S$ & $N$ \\
\hline Sumbana & $S$ & $N$ & $N$ \\
\hline
\end{tabular}

Tabela: Uma das estratégias de solução da tarefa lógica

A partir da tabela é então possível concluir quem vai para cada um dos destinos.

Como se pode ver na discussão dos grupos (ver apêndice) esta estratégia não foi previlegiada por nenhum deles.

No Grupo I, a discussão é geralmente orientada para uma perspectiva lógica, embora Maria e Dinis também se refiram aos detalhes da história, o que significa que foram capazes de reconhecer o contexto. Filipe, que se posiciona como uma espécie de líder do grupo, discute, desde o início, a exclusão de alternativas que revelam um ponto de vista lógico, afirmando uma conclusão sobre o destino de Magaia, excluindo Maputo, pois este pegará o carro emprestado de alguém do grupo que de facto, vai para Maputo. Mas ele ainda menciona o carro que é emprestado, mesmo que isso também seja irrelevante para tirar a conclusão. Maria concorda com Filipe, mas também reconhece que essas informações ainda não são suficientes para tomar uma decisão sobre os outros viajantes. No entanto, ela não avança o que poderia ser feito para descobrir o destino do Magaia. Depois disso, no turno 3, Filipe, repetindo o que foi descoberto, mostra confiança no seu raciocínio, considerando-o como verdade irrefutável e relevante. Novamente, estabelecendo-se como um líder na discussão, ele convida Dinis a contribuir para o debate. Dinis, no turno 4, também trabalha numa perspectiva lógica e chama a segunda frase de condição, termo que não é usado numa conversa quotidiana sobre pessoas que viajam, usando desse modo uma linguagem especializada. Ele também introduz a sua contribuição com uma afirmação categórica, dizendo que a proposição é útil para determinar 
a pessoa que vai à Maputo. A sua análise faz com que ele exclua Magaia e Manhique para o destino de Maputo. Esta interpretação depende muito do entendimento de que a frase 'o homem que vai à Maputo' qualifica esse homem desconhecido como o único que Vai à Maputo e que não qualifica a outra pessoa conectada com um 'e' na frase 'O homem que vai à Maputo e Manhique, ambos vão com seus filhos'. Dinis usa o termo "parece" para apresentar a sua conclusão que acha ser a "certa". O comentário de Maria, no turno 5, não parece basearse num princípio de exclusão. Ela justifica a sua conclusão com base na informação sobre o tempo de duração de uma viagem para determinado destino, chamando para a análise as suas vivências e não considerando o elemento fundamental "ir à Praia do Bilene". O raciocínio lógico de Filipe surge novamente no turno 6. Por sua vez, 11 Maria conclui que o destino de Magaia é o Kruger Park, justificando a sua escolha pelo carro emprestado e pelas crianças, evocando novamente as suas vivências.

Filipe, como dito acima, argumenta, principalmente, numa perspectiva lógica. Ele apenas mencionou informações relacionadas ao contexto uma vez, no turno 1, mas não usa isso como argumento, o que mostra que está em posse das regras de reconhecimento e de realização. Na conversa, ele assume a posição de moderador e os seus textos são legítimos para o contexto considerado. Dinis parece de igual modo saber utilizar os significados que extraiu das condições do problema para elaborar o seu discurso o que revela estar em posse das regras de reconhecimento e de realização, apesar de por vezes incluir no seu texto elementos detractores da comunicação, como quando se refere às crianças.

A orientação prática de Maria talvez seja algo esperado considerando o que foi mencionado sobre os alunos de classe trabalhadora. Maria não reconhece o contexto do problema, e por isso não está em altura de produzir os textos que eram esperados pelo entrevistador.

Em relação ao aproveitamento escolar, numa escala de 0-20, Maria tem médias 9 e 8 nas disciplinas de Português e Matemática, respectivamente, apesar de ser uma das mais fluentes em Português. Filipe na disciplina de Português tem média 13 e na disciplina de Matemática média 14, e é também fluente em Português. E Dinis na disciplina de Português tem média 10 e na disciplina de Matemática média 15. Estes dois participantes classificados como "da 
Guambe, R. Mutemba, B. \& Matavele, H. (2020). Etnomatemática e a construção de uma educação multicultural na escola. Revista Latinoamericana de Etnomatemática, 13(3), 00-00.DOI:

10.22267/relatem.20133.65

classe alta", têm notas melhores do que muitos dos alunos do estudo, talvez devido a estas características o desempenho deste grupo na pesquisa tenha sido melhor que o dos outros.

No Grupo II a Irene começa com a afirmação de que Manhique vai à Praia do Bilene, o que poderia ter sido feito numa perspectiva lógica, isto é, da segunda condição de Manhique não ir para Maputo e da primeira sobre Magaia também não ir para lá e nem à Praia do Bilene. Por sua vez, Sara pede explicitamente uma evidência para este destino de Manhique. A resposta de Irene, no turno 3, revela que ela tirou a conclusão do conhecimento relacionado ao contexto sobre ser agradável para as crianças estar na praia, e não duma análise lógica das três declarações. Por sua vez, Sara contesta o argumento, apontando que também há outra pessoa viajando com crianças (“A pessoa que vai para Maputo"). Então, no turno 5, Irene aparentemente muda para um argumento lógico por exclusão, apontando para a proposição "O homem que vai à Maputo e Manhique vão com os filhos". A partir disso, pode-se concluir que Manhique não pode ser a pessoa que está indo à Maputo. Sara parece tomar isso como argumento e afirma que, então, Manhique não pode ser quem vai à Maputo. Mas, por sua vez, Irene pede à Sara um argumento para essa conclusão, revelando que, ela talvez não tenha adoptado uma perspectiva lógica na sua afirmação anterior. Sara diz que concluiu isso desde a primeira declaração sobre Magaia pegar emprestado o carro de quem vai à Maputo. Mas a resposta de Sara não foi forte o suficiente para ser o principal argumento para tirar conclusões sobre o destino de Manhique. Em termos lógicos, era mais fácil apoiar a sua afirmação na conclusão anterior da Irene que exclui Maputo como destino de Manhique. No turno 9, Irene repete o seu argumento sobre as crianças, confirmando-se a ideia de que ela se apoia na experiência do seu dia-a-dia. Ela também argumenta com factos relacionados ao contexto para os outros dois destinos, tendo Sara concordado com ela e sugerido que se anotasse a conclusão. Aqui, ela inclui apenas informações relacionadas ao contexto como argumentos.

A apresentação da solução final mostra claramente a perspectiva de Sara ou local ou prática sobre a tarefa em questão, associando e destacando o destino dos viajantes e com quem eles estão viajando e o objectivo da viagem. Antes, durante a conversa, Sara insistia um pouco menos em argumentos relacionados ao contexto. Não está claro se sua afirmação no turno 8 foi baseada numa análise lógica ou não, mas é improvável. 
Do ponto de vista da teoria, deve-se esperar uma orientação local das duas alunas, já que Irene e Sara pertencem ao grupo de estatuto social baixo. Parece que na discussão elas priorizam os argumentos com base em seus conhecimentos sobre o que se faz, razoavelmente, naquela situação. As duas participantes não dominam as regras de reconhecimento, mas curiosamente a resposta sobre o destino de cada viajante, proposta, está correcta, apesar de não ser baseada em argumentos lógicos do contexto. Pelo facto de não terem reconhecido a tarefa como um problema de lógica, os seus argumentos basearam-se no quotidiano e não conseguiram produzir um texto legitimamente aceite.

$\mathrm{Na}$ análise das notas escolares os elementos deste grupo têm notas relativamente baixas. A Irene teve média 10 nas disciplinas de Português e Matemática e a Sara 10 na disciplina de Português e 9 em Matemática (abaixo de 50\%). Estas duas participantes comummente comunicam-se num dos idiomas locais, entretanto, seguindo a regra institucional discutiram a tarefa em Português.

No Grupo III a Ana afirma no turno 1 que o problema é "fácil" e depois que Jaime, que assume o papel de moderador, a incentiva no turno 2, ela aponta para as informações da terceira frase, mas acrescenta algo que não é dito no enunciado, que Magaia "fica fora do distrito". Por sua vez, Luísa fala sobre o valor da informação para a solução, mas não sugere nada. Em resposta, Ana conclui que Magaia não pode ser quem vai à Praia do Bilene. Esta conclusão não está de acordo com ele "ficar de fora do distrito", já que Praia do Bilene e Kruger Park estão ambos fora do distrito. É claro que é possível que ela tenha tirado sua conclusão por exclusão de um ponto de vista lógico, tendo em conta a localização geográfica dos dois destinos, pois a frase diz que Magaia fica mais tempo do que a pessoa que vai à Praia do Bilene. No turno 6, Jaime solicita atenção e se propõe a analisar a primeira afirmação a partir da qual ele conclui com razão que Magaia não pode ser a pessoa que vai à Maputo. Por sua vez, Luísa contribui com um ponto de vista puramente prático, argumentando que Manhique vai à praia porque leva as crianças para se divertirem. Por isso, ela ignora o significado de toda a frase que menciona duas pessoas levando seus filhos (a pessoa que vai à Maputo e Manhique vão com os filhos). Talvez ela tenha prestado atenção apenas à parte em que o nome é mencionado. Por sua vez, Jaime também adopta uma perspectiva prática e fala sobre a proximidade do Kruger Park, 
Guambe, R. Mutemba, B. \& Matavele, H. (2020). Etnomatemática e a construção de uma educação multicultural na escola. Revista Latinoamericana de Etnomatemática, 13(3), 00-00.DOI:

10.22267/relatem.20133.65

que ele supõe estar no distrito. Ana (turno 9) concorda com a discussão e ressalta que o Kruger Park fica no distrito e Sumbane vai para lá, como sugerido por Jaime. No turno 10, Luísa, pensando que Maputo é agora o destino de Magaia, conclui que essa pessoa vai para Maputo. Ana e Luísa basearem os seus argumentos em conhecimentos quotidianos durante toda a discussão, não tendo em momento algum percebido os significados das condições do problema. Contrariamente, Dinis em alguns momentos pareceu ter reconhecido o contexto, mas foi convencido pelos argumentos práticos das colegas. Sem as regras de reconhecimento estes participantes não foram capazes de produzir o texto esperado e diferentemente do grupo anterior apenas acertaram o destino de Manhique, usando um argumento não adequado ao contexto.

O aproveitamento escolar, dos participantes do Grupo III é fraco. A Ana teve média de 10 valores nas disciplinas de Português e Matemática, enquanto as médias de Luísa nas disciplinas de Português e Matemática foram 10 e 8 valores, respectivamente. No ano da pesquisa Jaime estava a fazer somente a secção de Ciências como repetente. A sua média na disciplina de Matemática foi de 13 valores

Em resumo, a discussão no Grupo I, foi orientada para uma análise lógica, o que pressupõe possuírem as regras de reconhecimento, e por isso tenham buscado as evidências para a sua argumentação nas proposições do problema. Contudo, a menina, intervindo com alguns argumentos duma perspectiva prática, indica falta de domínio destas regras. Uma vez tendo reconhecido o contexto, os alunos seleccionaram as evidências das proposições apresentadas no problema e construíram um texto adequado para responder a questão, mostrando domínio nas regras de realização.

A discussão no Grupo II foi mais inclinada para argumentos locais e práticos, embora alguns argumentos de Irene reflectissem uma análise lógica, que eram imediatamente rebatidos pela Sara. As tentativas de usar as proposições do problema para justificar as suas conclusões redundaram em fracasso, tendo as participantes usado com predominância argumentos relacionados ao contexto. Este procedimento sugere que as alunas não estão na posse de regras de reconhecimento que ajudem a identificar o contexto do problema sobre lógica 
formal. No entanto, a partir do seu raciocínio com base nas suas experiências do quotidiano conseguiram ter um resultado correcto, usando como argumento o facto de as crianças gostarem de praia ou de ser necessário ter um carro para se deslocar a Kruger Park. Assim, as expressões "viagem para determinados destinos", "existência de crianças", "duração da viagem", etc., foram as regras usadas para identificação do contexto do dia-a-dia (regras de reconhecimento) e partir daí elaborarem o argumento para a resposta a questão (regras de realização).

O Grupo III estava muito inclinado a argumentos referentes ao contexto prático e os participantes apresentaram uma solução que não seguia a lógica estabelecida no texto. $\mathrm{O}$ menino, de vez em quando, introduzia uma perspectiva lógica, mas também concordava com argumentos práticos apresentados pelas colegas do grupo, o que sugere falta de regras de reconhecimento do contexto da lógica formal. De forma similar ao Grupo II aqui os alunos reconhecem o contexto como do quotidiano e, por isso, seleccionaram significados idênticos aos daquele grupo. Na sua resposta trocaram os destinos dos dois viajantes que eram acompanhados de crianças, o que indica que o argumento usado foi com base na terceira proposição, por Maputo ficar mais longe do que Bilene, tendo sido descurada a primeira.

$\mathrm{Da}$ análise do aproveitamento escolar constatou-se haver uma relação entre as notas escolares nas disciplinas de Português e de Matemática e o desempenho dos alunos na pesquisa, o que pode significar que a posse de códigos de linguagem elaborados e princípios especializados de classificação influenciou o desempenho na resolução do problema no Grupo I constituido por Filipe, Dinis e Maria.Ana e Sara do Grupo II, com notas baixas nas disciplinas de Português e Matemática tiveram dificuldades em reconhecer o contexto e mostraram não estar na posse de códigos elaborados e princípios especializados. Estas reduziram os seus argumentos ao seu contexto quotidiano.

Os constituintes do Grupo III, Ana, Jaime e Luísa, cujas notas nas disciplinas de Português e Matemática são fracas, conforme foi visto anteriormente, também mostraram não estarem na posse de linguagem elaborada, evidenciado pela selecção de significados do quotidiano para fundamentar o seu raciocínio. 
Guambe, R. Mutemba, B. \& Matavele, H. (2020). Etnomatemática e a construção de uma educação multicultural na escola. Revista Latinoamericana de Etnomatemática, 13(3), 00-00.DOI:

10.22267/relatem.20133.65

\section{CONSIDERAÇÕES FINAIS}

A pesquisa visava explorar as estratégias dos alunos na resolução de um problema de lógica, tendo em atenção a condição social e linguística, e relacionar o desempenho na resolução com o sucesso escolar. A mesma apoiou-se na abordagem discursiva de aprendizagem de matemática com recursos teóricos a algumas noções de Brasil Bernstein (1990, 2000).

Todos os participantes no estudo podem ser considerados de classes baixas e/ou com poucas posses de subsistência, se comparados com as condições de aprendizagem nas escolas em áreas mais desenvolvidas do país ou noutros contextos. No entanto, com base no questionário sobre o seu histórico, alguns participantes foram identificados como oriundos de famílias de estatuto social e económico superior ao de outros. Portanto, as informações usadas para agrupamento de estatuto social reflectem muito a situação no contexto local. Foram, principalmente, os fatores económicos que posicionaram os participantes de maneira diferente na hierarquia de estatuto social. Contudo, o ganho de capital económico no contexto local não resulta, necessariamente, da educação, comparativamente superior dos membros da família. Nessa base, os alunos foram classificados como pertencentes a classe alta, média ou baixa.

Na resolução da questão lógica foram extraídas as seguintes ilações:

- Na discussão e solução do problema verbal dominaram as abordagens relacionadas com o contexto, isto é, os alunos discutiam olhando para a realidade do sujeito e não necessariamente a relação das variáveis.

- Os alunos da classe média e alta mostraram ter posse das regras de reconhecimento e de realização.

- Na questão de género há uma grande tendência das raparigas recorrerem à estratégia informal, isto é, ao entendimento quotidiano

- Há pequenas evidências de que o baixo estatuto social de alguns alunos foi compensado pela sua flexibilidade linguística na resolução do problema 
Estas ilações corroboram, ou melhor dizendo coadunam com a teoria de Bernstein (1996) quando diz que a produção de um texto legitimamente aceite na aula de Matemática, requer não apenas que o aluno reconheça o contexto do problema, mas também, que adquira as regras de realização neste contexto.

Das soluções da tarefa de lógica, foi visível que as abordagens contextuais dominavam, mesmo que os alunos fossem de grupos diferentes, o que sugere que independentemente da classe social, a maioria dos alunos não possuía as regras de reconhecimento no contexto da lógica formal, e por via disso, não conseguiu elaborar textos legitimamente aceites. A base de estratificação dos participantes desta pesquisa pode explicar este resultado, uma vez que não há muita diferença no ambiente familiar que rodeia estas crianças, e por isso, são mínimas as diferenças das oportunidades de experiências e enriquecimento que são proporcionadas a cada uma delas, o que poderia fazer diferença no seu desempenho.

As diferenças de género eram mais óbvias, no sentido de que as raparigas mostraram mais tendência a atender às características relacionadas ao contexto local, incluindo as que foram classificadas como de classe média.

O aproveitamento em termos de notas escolares reflectiu-se, em certa medida, na forma como os participantes orientaram as suas respostas. Os com melhor aproveitamento mostraram possuir as regras de reconhecimento e a partir dos significados construíram textos legitimamente aceites, enquanto os com baixo aproveitamento baseavam-se nas suas vivências do quotidiano para produzir os seus textos, o que revela falta de reconhecimento do contexto do problema.

Adicionalmente notou-se que uma parte dos participantes teve dificuldades em interpretar o texto como um todo, isto é, de ver e perceber que as frases eram inter-relacionadas e, por isso, a solução do problema dependia das três condições apresentadas no texto.

\section{REFERÊNCIAS BIBLIOGRÁFICAS}

Bernstein, B. (1990). Pedagogy, Symbolic Control and Identity: Theory, research, critique. Revised edition. London, UK: Rowman \& Littlefield. 
Guambe, R. Mutemba, B. \& Matavele, H. (2020). Etnomatemática e a construção de uma educação multicultural na escola. Revista Latinoamericana de Etnomatemática, 13(3), 00-00.DOI:

$10.22267 /$ relatem.20133.65

Bernstein, B. (1996). Pedagogy, symbolic, control and identity: Theory, research, critique. Oxford, England: Taylor \& Francis.

Bernstein, B. (2000). Pedagogy, symbolic control and identity: Theory, research and critique. Revised edition. Oxford: Roman \& Littlefield.

Capelin, E. T \& Martins, C. A. R. (2016). O estudo da lógica no ensino básico. XII Encontro Nacional de Educação Matemática. Educação Matemática na Contemporaneidade: desafios e possibilidades. São Paulo, 2941-2951

Cooper, B., \& Dunne, M. (2000). Assessing children's mathematical knowledge: Social class, sex and problem solving. Buckingham, UK: Open University Press.

Gellert, U. (2009). Analysing accounts, discourse and mathematics classroom interaction. Reflections on qualitative methodology. In: R. Kaasila (Hrsg.) Matematiikan ja luonnontieteiden opetuksen tutkimuspäivät -Rovaniemi: Lapin yliopistopaino., 9-34.

INE (2019). IV recenseamento geral da população e habitação 2017. Resultados definitivos' Moçambique: Maputo.

Jablonka, E. (2007). Mathematical literacy: Die verflüchtigung eines ambitionierten testkonstrukts. In I. T. Jahnke, \& W. Meyerhöferr, (Eds.), Pisa \& Co: Kritik eines programms (pp. 249-282). Hildesheim, Germany: Franzbecker.

Munhoz, D. J., Rossato, E., Souza, F. M., Canónico, M. M. \& Costa, T. Q. (2013). Estudo comparativo do raciocínio lógico entre alunos superdotados e não superdotados. VIII Encontro da Associação Brasileira de pesquisadores em educação especial. Londrina, 2941- 2951.

Taylor, N., \& Vinjevold, P. (1999). Teaching and learning in South African schools. In N. Taylor and P. Vinjevold (Eds.) Getting learning right: Report of the President's education initiative research project (pp. 131-162). Braamfontein: Joint Education Trust. 
Zevenbergen, R. (1995). The research story collection. In J. Mousley, M. Robson, \& D. Calquhoun (Ed.), Discourse analysis of the classroom (pp. 78-87). Geelong, Australia: Deakin University Press.

Zevenbergen, R. (1998). Gender, media and conservative politics. In C. Keitel (Ed.), Social justice and mathematics education: Gender, class ethnicity and politics of schooling (pp. 59-68). Germany: IOWME and Freie Universitat Berlin.

Zevenbergen, R. (2000). Cracking the code of mathematics: school success as a functional of linguistic, social and cultural background. In J. Boaler (Ed.), Multiple perspectives on Mathematics teaching and learning (pp. 201-223). Westport, CT: Ablex.

Zevenbergen, R. \& Lerman S., (2004). The Socio-political Context of the Mathematics Classroom - in Researching the Socio-Political Dimensions of Mathematics Education 
Guambe, R. Mutemba, B. \& Matavele, H. (2020). Etnomatemática e a construção de uma educação

multicultural na escola. Revista Latinoamericana de Etnomatemática, 13(3), 00-00.DOI:

$10.22267 /$ relatem.20133.65

\section{Apêndice}

\section{Transcrição das entrevistas}

\section{Grupo I}

1. Filipe: Podemos afirmar que Magaia não Vai à Maputo, porque ele pede emprestado o carro da pessoa que vai à Maputo...

2. Maria: Sim, eu concordo, ele não vai à Maputo, mas isso não basta para saber para onde está indo...

3. Filipe: Bem, antes de tudo, ele não vai à Maputo. Dinis tem alguma ideia sobre isso?

4. Dinis: A segunda frase ou segunda condição pode ser útil para conhecer a pessoa que Vai à Maputo porque diz: O homem que Vai à Maputo e -Manhique vão com os filhos. Parece certo que Magaia e Manhique não vão a Maputo, então...

5. Maria: Sim, você está certo, Manhique está indo para a praia do Bilene, como se diz que ele estará fora do distrito menos tempo que Magaia, de acordo com a terceira frase...

6. Filipe: Ok, vamos encontrar o destino de Magaia sabendo que não vai à Maputo e ele não vai à Praia do Bilene de acordo com a última frase...

7. Dinis: Hah, então...

8. Maria: Claro que ele vai para a Reserva do Parque Kruger, claro é fácil, como você vê...

9. Dinis: Ok, agora e desde a segunda frase sabemos que Manhique não vai à Maputo. Quem vai lá é Sumbane, não é?

10. Filipe: Se isso for verdade, significa que Manhique vai para a praia de Bilene.

11. Maria: Sim, acho que Magaia vai ao Parque Kruger enquanto ele pega emprestado um carro de Sumbane que vai à Maputo com seus filhos e Manhique também com seus filhos vai à Praia do Bilene.

12. Dinis: Sim, ir à Maputo e Praia do Bilene com crianças é bom, é tão bom...

13. Filipe: Agora a resposta final para a tarefa dada é...

14. Maria: o destino de Magaia é Kruger Park. O destino de Sumbane é Maputo e ...

15. Dinis: Finalmente, Manhique vai à Praia de Bilene com as crianças 


\section{Grupo II}

1. Irene: Eu acho que, se eu entendi, Manhique vai à Praia do Bilene porque ele não está indo para o Kruger Park e nem à Maputo.

2. Sara: Como você acha que Manhique vai para Bilene? Donde você tira essa conclusão? Por favor explique.

3. Irene: Na segunda frase, diz-se que Manhique vai com seus filhos e é muito bom ir à praia com...

4. Sara: A pessoa que vai para Maputo também vai junto com os filhos. Ele poderia ser o Manhique.

5. Irene: Não deve ser o Manhique, observe a frase que o homem que vai à Maputo e Manhique vão com os filhos. Portanto, exclui-se a hipótese de ele ir à Maputo.

6. Sara: Sim, você está certa, sabemos que Manhique não vai para Maputo.

7. Irene: Como e de onde você pode afirmar?

8. Sara: Desde a primeira frase ao dizer que Magaia pega emprestado um carro da pessoa que vai à Maputo.

9. Irene: Ok, você vê que é correcto afirmar. A pessoa que vai à Praia do Bilene é Manhique porque viaja com crianças. Magaia vai ao Kruger Park para o turismo, porque ele pega emprestado o carro de Sumbane, que vai à Maputo.

10. Sara: Faz sentido, está correcto, agora escrevemos a resposta completa:

- Magaia vai ao Kruger Park e é por isso que pede emprestado um carro da pessoa que vai à Maputo.

- Sumbane leva seus filhos para desfrutar de Maputo que viaja para Maputo.

- Manhique vai para a praia de Bilene e fica mais tempo do que a pessoa que vai ao Kruger Park.

11. Irene: Isso aí. É tudo.

\section{Grupo III}

1. Ana: Sim, eu estou pronta, é tão fácil interpretar...

2. Jaime: Sim, vá em frente... 
Guambe, R. Mutemba, B. \& Matavele, H. (2020). Etnomatemática e a construção de uma educação multicultural na escola. Revista Latinoamericana de Etnomatemática, 13(3), 00-00.DOI:

10.22267/relatem.20133.65

3. Ana: Sim, Magaia vai ficar fora do distrito por muito tempo em comparação com a pessoa que vai à Praia do Bilene...

4. Luísa: Sua declaração nos ajuda para quê e de que maneira responder à pergunta?

5. Ana: Imediatamente podemos assumir que ele não vai à Praia do Bilene...

6. Jaime: E então...? Atenção, por favor, na primeira frase, diz-se que Magaia pede emprestado carro daquele que está indo para Maputo, o que significa que ele não vai à Maputo.

7. Luísa: No meu entendimento, quem está indo à Praia do Bilene é Manhique, porque ele leva seus filhos para curtir...

8. Jaime: Parece certo. Podemos assumir que Sumbane ficará no distrito, quero dizer que ele vai ao Kruger Park perto da fronteira com a África do Sul.

9. Ana: Sim, o Kruger Park está neste distrito. Sumbane vai lá.

10. Luísa: Perfeito, você está certo, significa que quem vai à Maputo é Magaia

11. Jaime: Observe que Magaia pegou emprestado o carro da pessoa que vai à Maputo. Logo, não faria sentido dizer que Magaia viaja para Maputo.

12. Luísa: Esse era o plano, nenhum indivíduo viajou ainda. Assumimos o que concluímos Então....

13. Ana: Sim, eu concordo, respondendo à pergunta que dizemos:

Magaia vai à Maputo e ficará fora do distrito por mais tempo do que a pessoa que vai à Praia do Bilene.

Manhique está indo à Praia do Bilene porque viaja com seus filhos.

Sumbane vai à Kruger Park porque ficará no distrito.

14. Jaime: Foi tudo e assim terminamos. 


\section{Inquérito administrado aos participantes}

I - IDENTIFICAÇÃO Data: 1

Código:

1. Nome:

Classe

2. Sexo: (Assinale com $\boldsymbol{X}$ no rectângulo apropriado)

\begin{tabular}{|l|l|l|l|}
\hline Masculino & & Feminino & \\
\hline
\end{tabular}

3. Idade [em anos]: (Assinale com $\boldsymbol{X}$ no rectângulo apropriado)

\begin{tabular}{|l|l|l|l|l|}
\hline Entre 13-14 & Entre 15-16 & Entre 17-18 & Entre 19-20 & Entre 21 - 22 \\
\hline & & & & \\
\hline
\end{tabular}

\section{Local de Nascimento}

4.1. Província:

Distrito

4.2. Nasceu num meio (Assinale com $\boldsymbol{X}$ a opção apropriada)

\begin{tabular}{|l|c|c|}
\hline Urbano & Suburbano & Rural \\
\hline & & \\
\hline
\end{tabular}

\section{Línguas}

5.1. Em que língua aprendeu a falar (língua materna)?

5.2. Língua em que se comunica correntemente:

\begin{tabular}{|l|l|}
\hline 1. Em casa (com os pais e irmãos) & \\
\hline 2. Com os amigos & \\
\hline
\end{tabular}


Guambe, R. Mutemba, B. \& Matavele, H. (2020). Etnomatemática e a construção de uma educação multicultural na escola. Revista Latinoamericana de Etnomatemática, 13(3), 00-00.DOI:

10.22267/relatem.20133.65

\begin{tabular}{|l|l|}
\hline 3. Com os vizinhos & \\
\hline 4. Com os colegas & \\
\hline
\end{tabular}

\section{II - SITUAÇ̃̃o SÓCIO - FAMILIAR}

6. Encarregado de educação: (Assinale com $\boldsymbol{X}$ a opção apropriada)

\begin{tabular}{|l|l|}
\hline Pai & \\
\hline Mãe & \\
\hline Tio/Tia & \\
\hline Irmão/Irmã & \\
\hline Avô/Avó & \\
\hline Outro* & \\
\hline
\end{tabular}

* Indique o grau de parentesco

7. Ocupação dos pais/encarregados de educação

\begin{tabular}{|l|l|l|l|l|}
\hline & Função Pública & Empresa do Estado & Empresa Privada & Conta própria** \\
\hline Pai & & & & \\
\hline Mãe & & & & \\
\hline Encarregado & & & & \\
\hline
\end{tabular}

7.1. **Caso trabalhe por conta própria é: (Assinale com $\boldsymbol{X}$ a opção apropriada)

\begin{tabular}{|l|l|l|l|l|l|l|l|}
\hline $\begin{array}{l}\text { Agric } \\
\text { ultor }\end{array}$ & Criador & Canalizador & Electricista & Carpinteiro & Pedreiro & Pescador & Liberal*** \\
\hline & & & & & & & \\
\hline
\end{tabular}


7.2. ***Se ocupação liberal indique (Assinale com $\boldsymbol{X}$ a opção apropriada)

\begin{tabular}{|l|l|l|l|l|l|l|l|l|}
\hline Advogado & Médico & Curandeiro & Parteira & $\begin{array}{l}\text { Fotógra } \\
\text { fo }\end{array}$ & Pintor & Explicador & Artesão & Outro \\
\hline & & & & & & & & \\
\hline
\end{tabular}

8. Vive (Assinale com $\boldsymbol{X}$ a opção apropriada)

\begin{tabular}{|l|l|l|l|l|l|l|l|l|}
\hline C/Pais & C/Tios & C/Avos & C/Cunhado/as & C/Irmã/ão & C/Amigos & C/Primos & No Lar & $\begin{array}{l}\text { Na } \\
\text { Pensão }\end{array}$ \\
\hline & & & & & & & & \\
\hline
\end{tabular}

\section{Habitação}

9.1. A casa onde vive é de: (Assinale com $X$ a opção apropriada)

\begin{tabular}{|l|l|l|}
\hline $\mathbf{1}$ & Material precário: caniço, palha, capim, adobe & \\
\hline $\mathbf{2}$ & Madeira e Zinco & \\
\hline $\mathbf{3}$ & Alvenaria (material convencional) & \\
\hline
\end{tabular}

9.2. A casa dos pais é de: (Assinale com $\boldsymbol{X}$ a opção apropriada)

\begin{tabular}{|l|l|l|}
\hline $\mathbf{1}$ & Material precário: caniço, palha, capim, adobe & \\
\hline $\mathbf{2}$ & Madeira e Zinco & \\
\hline $\mathbf{3}$ & Alvenaria (material convencional) & \\
\hline
\end{tabular}

9. 3. A habitação onde vive tem (Assinale com $\boldsymbol{X}$ a opção apropriada)

\begin{tabular}{|l|l|l|l|}
\hline Electricidade & Água canalizada & Receptor da Rádio & Receptor da Televisão \\
\hline & & & \\
\hline
\end{tabular}


Guambe, R. Mutemba, B. \& Matavele, H. (2020). Etnomatemática e a construção de uma educação multicultural na escola. Revista Latinoamericana de Etnomatemática, 13(3), 00-00.DOI:

10. Refeições

10.2. Quais são?

(Assinale com $\boldsymbol{X}$ a opção apropriada)

\begin{tabular}{|l|l|l|l|l|l|l|l|}
\hline Pequeno-almoço & & Almoço & & Lanche & & Jantar & \\
\hline
\end{tabular}

11. Composição numérica do agregado familiar (Assinale com $\boldsymbol{X}$ a opção apropriada)

\begin{tabular}{|l|l|l|l|l|l|l|l|l|l|l|l|l|l|l|l|}
\hline $1-3$ & $4-5$ & & $6-7$ & & $8-9$ & & $10-11$ & & $12-13$ & & $14-15$ & & +15 & \\
\hline
\end{tabular}

12. Distância da casa para escola (em quilómetros) (Assinale com $\boldsymbol{X}$ a opção apropriada)

\begin{tabular}{|l|l|l|l|l|l|l|l|l|l|l|}
\hline Até 1 & $2-3$ & $4-5$ & $4-5$ & $5-6$ & $6-7$ & $7-8$ & $8-9$ & $9-10$ & $10-11$ & $>11$ \\
\hline & & & & & & & & & & \\
\hline
\end{tabular}

13. Meio de transporte usado regularmente de e para escola (Assinale com $\boldsymbol{X}$ a opção)

\begin{tabular}{|l|l|l|l|}
\hline A pé & Bicicleta & Carro pessoal/familiar & Transporte público \\
\hline & & & \\
\hline
\end{tabular}

